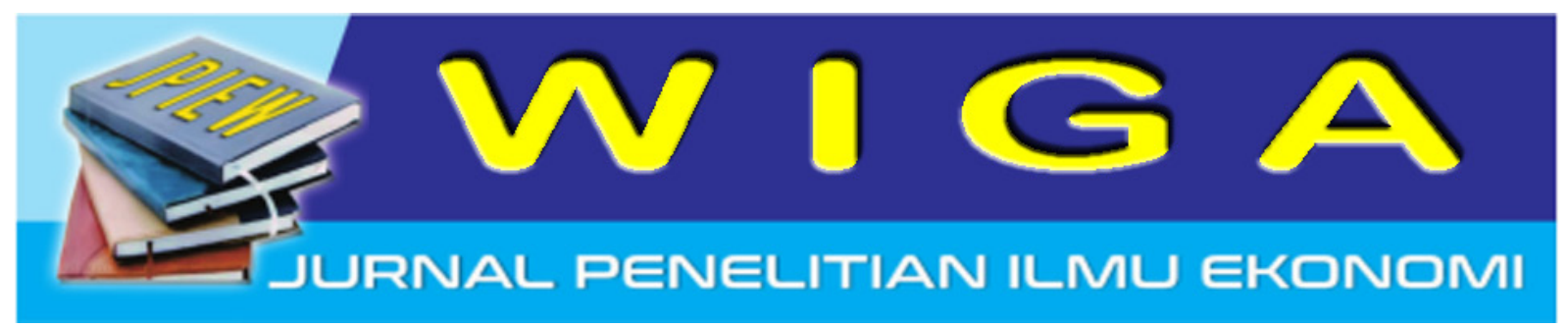

\title{
A MODEL INTEGRATING CULTURAL DIVERSITY EDUCATION INTO THE ACCOUNTING CURRICULUM IN HIGHER INSTITUTION
}

\author{
Muslichah, Wiyarni \\ STIE Malangkuçeçwara Malang \\ muslichahmachali@yahoo.com
}

\begin{abstract}
Education is one of the elements of character formation and development of human beings. Cultural diversity education is a conscious effort to develop personality inside and outside school to learn about the different kinds of social status, race, ethnicity, religion in order to create a good personality in dealing with issues of cultural diversity. In this article we propose a framework of cultural diversity education in academic program for accounting students. The education emphasizes knowledge of and interaction with other cultures and ethnicities.Cultural diversity education and understanding of the relativity of cultural differences is a our growing sense and awareness of the importance of respect, recognize and accept the diversity that already exist
\end{abstract}

\section{INTRODUCTION}

Theglobal trends on human migrations to a growing diversestudent population in higher institutions in Indonesia are increasing. Scholars and inserviceteachers try to respond to this student diversity throughmaking changes in curriculum and instruction. They try to develop an understanding of students' backgrounds, create relevant instructional contexts, and promoteenactment of public policy initiatives that improve students'learning experience and their process of studying in higher institutions. Multicultural education coursework and field experiences in student educationprograms are thought to be important avenues for developingpositive attitudes toward cultural diversity and for developingpractices that promote cultural pluralism.

Indonesia is a culturally-diverse country. Many different religions and cultures from many provinces are now seen living side by side in many places. One of the biggest questions facing Indonesian today is how to deal with a culturally diverse citizenry and then promote unity. Indonesians should appreciate differences among culture for the following reasons. Firstly, Indonesia is vulnerable to separation 
for its archipelago and culture diversity. Raising tolerance among people is the best way to maintain the unity among differences. Many ways or cultures of living are equally legal, even if they are not regarded as normal by some people. If a society claims to be tolerant of personal choice, then it must respect the personal choice to retain their heritage. Then, unity of the nation can be preserved. Secondly, Indonesians must recognize that every culture has different customs and beliefs. Thus, people are forbidden to make judgments of comparative value, for it is measuring something unmeasured. A plurality of nations, especially in the modern era, can allow for cultural development and cultural exchange that benefits both parties. The cross-cultural understanding among cultures makes the world a better place and preserves the unity of the nation. Lastly, raising nationalism is one way to preserve unity of the nation. It is a sense of fellow feeling between group members. This promotes cooperation and social cohesion within the group. The sense of social cooperation makes welfare, social security and medical programs much more likely and stronger. Cultural differences are sometime a sensitive matter for people. Indonesian people must teach younger generation about the importance of the cultural identity and nationalism to promote unity of the nation.

The first chance that many students have to encounter and interact with someone from a different race or ethnicity will be a college or university. Orfield\&Kurlaender (2001) state that students tend to have minimal interaction with other racial backgrounds before college.Some of the factors that hamper equality of educational opportunity are incidents of discrimination and harassment against members of the campuscommunity based on sexual orientation, race, age, ethnicity, religion and gender. Colleges and universities in Indonesia are having an influx of students from various communities of Indonesia. This poses a continuing challenge growing with the size of the International and other minority student populations on campus, problems forcolleges and universities in terms of diversity.

Little research has focused on analyzing cultural diversity within higher institutions. Prior research on Cultural Diversity Education (CDE) investigating cultural factors in African American student performance have found that building on students' cultural assets enriches learning, recall, and cognitive performance (Boykin, et al., 2005; Cunningham, 2005; Cunningham \& Boykin, 2005; Hurley, Allen, \& Boykin, 2009). Cuff (2014) examined cultural diversity in higher education learning, he especially investigated the incorporation of movement expressiveness in the learning contexts on paired associate learning of African American college students. $\mathrm{He}$ found thatproviding fundamental cultural themes (i.e. movement expressiveness) in classroomcontexts is beneficial to the school performance of African American students. Sanner et al. (2010) investigated the effectiveness of a cultural diversity forum on students' cultural sensitivity as measured by their openness to diversity. The findings suggested that an educational format like the cultural diversity forum can promote students'cultural sensitivity. Furthermore, Paternotte et al. (2014) investigates the current formal status of cultural diversity training in the Netherlands, which is a multiethnic country with recently updated medical curriculum documents. The findings of the research show that Cultural diversity aspects were more prominently described in the curriculum documents for undergraduate 
education than in those for postgraduate education. The most specific information about cultural diversity was found in the blueprint for undergraduate medical education. In the postgraduate curriculum documents, attention to cultural diversity differed among specialties and was mainly superficial.

As the development of science and technology, society demands to graduates of universities are also increasingly critical. College graduates in the increasingly fierce competition is expected to have capabilities that include personal ability, academic ability and professional capability. In this case, CDE assumed the role of general education courses that are delivering students to have the personal ability. Students are expected to put themselves as members of society are inseparable from the community and the ability to have a social responsibility. The responsibility was realized with the participation of students in solving social problems in society accordance with the knowledge they have. CDE has objectives include developing awareness of students about of diversity, equality and human dignity as well as individual and social beings in public life. This goal is particularly necessary to realize, look at this era of globalization, many people who do not care about diversity, equality, and dignity in public life. This simple knowledge is very worth noting because it is fundamental to the life of society and harmonious. CDE be an alternative to the instrument or tool in solving social and cultural problems in social life. As we know, the function of CDE is an effort that is expected to provide basic knowledge and general understanding of the concepts that were developed to assess social phenomena of culture in order responsiveness, perception, and reasoning of students in the face of social and cultural environment can be improved so that the sensitivity students on the environment becomes greater.

Integration of CDE into higherinstituitions connotes a multicultural society where many different groups of people mutually coexist and respect each other's way of living. The purpose of this articleis todiscuss the important role ofCDE in accounting higher institutions. The studies about CDE have been conducted by several researchers such as Paternotte et al.(2014; Dogra et al.(2011); and Sanner et al.(2010). Their studies focus on medical institutions. Therefore this article wants to discuss the important role of $\mathrm{CDE}$ in accounting program in higher education.

\section{LITERATURE REVIEW Cultural Diversity}

Culture can be defined as a dynamic system of values, beliefs, and behaviors that influences how people experience and respond to the world around them. For many, cultural diversity can be referred to as "distinctions in the lived experiences, and the related perception of and reactions to those experiences that serve to differentiate collective populations from one another" (Marshall, 2002). Marshall (2002) argues that in defining cultural diversity we need to go beyond culture and focus on its relational aspect by emphasizing the relationships of interdependence among groups in the context of unequal power and domination (Bannerji, 2000; James, 2000).

Culture and education are inextricably intertwined, and students' perspectives and worldviews influence their experiences in educational environments (Adams, 1992; Gay, 2000; Jones, 2004; Wlodkowski\& Ginsberg, 1995). Culture plays a part in shaping the ways in which students learn and communicate, how they 
relate to other students and instructors, their motivation levels, and their sense of what is worth learning. The degree to which students feel comfortable in the learning environment will depend on the congruence between their cultural background and the dominant culture of the educational institution (Shibao\&Zenobia, 2007).

In addition to the responsibility that institutions of higher education have in meeting the needs of diverse students, there is evidence that increased diversity in higher education institutions can benefit students from all backgrounds both from majority as well as from minority groups (Casteneda, 2004). These benefits include an improvement in intergroup relations and campus climate, increased opportunities for accessing support and mentoring systems, opportunities for acquiring broader perspectives and viewpoints, and participating in complex discussions, all of which can contribute to increased learning. There are a growing number of empirical studies that provide support for these benefits. In a study designed to examine the relationship between the diversity of the student body and interactions among students, Pike and Kuh (2006) found that a diverse student population is related to increased interaction among diverse groups of students, and that the more diverse the student population, the greater the exposure to diverse perspectives and viewpoints. In another study, Gurin (1999) found that students acquire a very broad range of skills, motivations, values, and cognitive capacities from diverse peers when provided with the appropriate opportunities to do so. In addition, campus communities that are more racially diverse tend to create more richly varied educational experiences that prepare them better for participation in a democratic society (Chang,Denson, Sáenz\&Misa, 2006).
Furthermore, learning environments that are supportive of diversity can lead to more openness to diversity, critical thinking skills and greater personal development $(\mathrm{Hu}$ \&Kuh, 2003)

\section{Multicultural Education}

Earlier literature indicated that when the minority student is not re-socialized, it was commonly believed that alienation or marginality would occur (Mansell, 1981), leading to the further segregation of the individual from the majority and a negative influence on group acceptance (JulesRossette, 1986). Group acceptance was once seen as key to positive academic achievement. Recent research, however, indicates that only cultural adaptation "is conducive to maximizing the human wellbeing and academic success of students" (Gay, 1993, p. 7) Such adaptation must occur not only among students, but on a systemic basis as well. This can only be accomplished through the process of positive attitudes toward cultural diversity and cultural pluralism on the part of educational administrators.

Banks and Banks (1995) define multicultural education as a field of study and an emerging discipline to create educational opportunities for students from diverse racial, ethnic, social class, and cultural groups. One of its important goals is to help all students to acquire the knowledge, attitudes, and skills needed to function effectively in a pluralistic democratic society and to interact, negotiate, and communicate with peoples from diverse groups in order to create a civic and moral community that works for the common good" (p. 28).Rosado (1996) offers an operational definition of multiculturalism. Rosado (1996) stated that multiculturalism is a system of beliefs and behaviors that recognizes and respects the 
presence of all diverse groups in an organization or society, acknowledges and values their socio-cultural differences, and encourages and enables their continued contribution within an inclusive cultural context which empowers all within the organization or society.

\section{Integrating Multicultural Curriculum}

Colleges and universities can play a role in transforming or changing the campus environment in order to meet the needs of all students. Colleges and universities must first shift their thinking to determine that diversity is central to the institution's overall priorities for teaching and learning. This requires a change in how students are regarded or valued. Enacting diverse learning environments will help them realize the potential benefits of racially/ethnically diverse student environments and intentionally create opportunities for learning and interacting across communities of difference. Acknowledging and incorporating positive cultural interaction in the classroom, Wilson (1997) says this approach is based on consensus budding, respect, and fostering cultural pluralism within ethnic societies and is achieved by an integrated curriculum, social activities, administrative support and staff training. Wilson (1997) submits that multicultural education must, in order to achieve its purposes, first, foster a learning environment that supports positive interracial contact; second, a multicultural curriculum; third, positive teacher expectations; fourth, administrative support; and fifth, teacher training workshops. Through multicultural education, fear, ignorance and personal detachment may be reduced in students and teachers and that stereotyping, prejudice, racism and bigotry can be eliminated (Tanya, 2002).
Grant (1976) targets five major approaches to multicultural education and classifies them according to their assumptions for the values, strategies, target groups, and outcomes. First, approach that emphasizes in educational opportunity for students from different cultural backgrounds (Benevolent Multiculturalism) (Hilliard,1974);second, approach that emphasizes to teach students to value cultural differences, to understand the meaning of the culture concept, and to accept others' right to be different; third, approach that emphasizes to education for cultural plurality; fourth, approach that emphasizes to bicultural education - produce learners who have competencies in and can operate successfully in two different cultures; and the last approach is multicultural education as the normal human experience (Goodenough, 1976)to promote competence in multiple societies.

Banks (1993) identifies four approaches to education. The four approaches are teaching about contributions of culturally different groups and individuals; an additive approach in which lessons and units of study are supplements or appendages to existing curricula; a transformation approach in which the basic nature of curriculum and instruction are changed to reflect the perspective and experiences of diverse cultural, ethnic, racial, and social groups; anda decision-making and social action approach that teaches students how to clarify their ethnic and cultural values and to engage in sociopolitical action for greater equality, freedom, and justice for everyone (Tanya, 2002).

Rosado (1996), offers a concept called Total Quality Diversity as a model of structural change for organizations. Rosado (1996) stated that managing diversity should be a comprehensive and holistic process. He 
indicates that one common misconception is that the mere presence of an ethnically and racially diverse student population, due to legal, moral, or social imperatives, makes a school multicultural. Specifically, Rosado (1996) says what makes a school multicultural involves whether its "five P's" (Perspectives, Policies, Programs, Personnel, Practices) implement the following four imperatives forming the basis of Multicultural Education: reflect the heterogeneity of the school (the dynamic of Affirmative Action); are sensitive to the needs of the various groups comprising the student population (the dynamic of valuing differences); incorporate their contributions to the overall mission of the school (the dynamic of managing diversity); andcreate a cultural and social ambiance that is inclusive and empowers all groups (the dynamic of living diversity).

Rosado (1996) then offers multiculturalism as a part of an on-going process that enables administrators, teachers and their students to become world citizens. Word citizens are persons who are able to transcend their own racial/ethnic, gender, cultural, and socio-political reality.

\section{DISCUSSION}

As a final stopping point for young adults before the enter the workforce, higher institutions has an important role to play in ensuring that the next generation of workers is up to the growing challenges of an increasingly diverse global community. All students studying in higher institution should be equipped with sufficient knowledge to deal with cultural diversity. As stated by Bulut\& Bars (2013) that a purpose of higher education is to preserve, enrich, and transmit the culture. Exposure to racial diversity in college has long term benefit of preparing students to understand multiple perspectives, to negotiate conflict, and to relate to different worldviews (Jayakumar, 2008).

This article uses Kitano (1997) model as approach to integrate cultural diversity into accounting curriculum in higher education. The model has three types, they are the intercultural education model, the multicultural education model, and the antiracist education model. Each of these models can be used to create change at different levels and spheres of influence, including the self, classroom, institution, and community (Kitano, 1997). These models can be used to explore and understand the different elements to consider when teaching for cultural diversity and can provide a starting point to understand the role that faculty members can play at different levels.

The first model is an intercultural education model for the development of individual diversity that can be used by faculty members to reflect on their own attitudes towards diversity and to promote and influence the diversity development of their students (Chávez, Guido-DiBrito\& Mallory, 2003). The second model is a multicultural education model (Banks, 1997a, 1997b) that provides a framework for curriculum change and reform and can be applied at the level of the self and the classroom. Third, a model based on an antiracist approach to education is included (Dei, James-Wilson \&Zine, 2001). Although all three models provide valuable insights into the task of addressing issues of cultural diversity, this article suggests that the antiracist model is the most inclusive one for implementing changes required in higher education institutions because it provides a critical integrative framework. It operates at all four levels of influence: the self, classroom, institution, and community. It addresses issues of difference and diversity at the level of the individual, provides 
strategies for both curriculum and pedagogical change, and addresses issues of power inequities in educational institutions (Shibao\&Zenobia, 2007).

Based on the literature review above, we propose the framework of cultural diversity course in academic program for accounting students. The course emphasizes knowledge of and interaction with other cultures and ethnicities. The syllabus contains information that affirms diversity, is culturally responsive, andexamines discipline-specific theory and practice using multicultural curriculum theoryand practice. The essential content on discussion topics and key points are first, race, ethnicity, identity and learning; second,racial/ethnic identity development; andcase studies in racial/ethnic identity development.

Primarytext/resources for cultural diversity course are:

- Banks, James A. (2002). Introduction to Multicultural Education, 3rd edition. Boston:Allyn\& Bacon.

- Bucher, Richard. (2000). Diversity Consciousness. New Jersey: Prentice Hall.

Below is the outline of the cultural diversity course in accounting:

1. Class 1 and 2: lecture on practical guidelines to culturally competencies.

2. Class 3: views the video related with cultural diversity and describe the term. Discuss the content of the video.

3. Class 4: lecture and discuss the improving cross-culture.

4. Class 5: brief lecture on racial stereotypes based on content of textbook, followed by class discussion.

5. Class 6: brief lecture on language and communication style in culturally competencies, followed by class discussion.

6. Class 7: brief lecture on cultural behavior and cultural conflict in accounting profession based on textbook, followed by class discussion.

7. Class 8: term experience oral presentations.

The course template for cultural diversity provides a format that can be modified or expanded based on an individual institution. Numerous other resources such as diversity course for accounting profession students. The resources provide skills, techniques, and class experiences that could be incorporated into a diversity course depending on the contact hour allocation of the course.

\section{CONCLUSION}

Indonesian society Condition is very pluralistic from the aspects of race, ethnicity, religion and social status. This provide exceptional contributions to the development and dynamics in society. Such conditions allow the clash between cultures, between race, ethnicity, religion and values prevailing in society. Cultural diversity education is a series of concepts, user behavior was officially formulated through the curriculum, regulations, methods of learning, the ability of teachers, relationships between schools and the community in terms of multiculturalism. Education that puts the issue of diversity in society is the core of cultural diversity education. The cultural diversity education will create sympathetic attitude that increase respect, appreciation, and empathy against faiths and different cultures

\section{REFERENCES}


Adams, M. (1992).Cultural inclusion in the American college classroom.InL.L.B. Border \& N. V. Chism (Eds.), Teaching for diversity. New Directions forTeaching and Learning, 49 (pp. 5-17). San Francisco: JosseyBass.

Banks, J.A. (1993a). Multicultural education: Development, dimensions and challenges.Phi Delta Kappan.75 .2228.

Banks, J.A. (1995). Multicultural education and modification of students' racial attitudes.InW. D. Hawley \& A. W. Jackson (Eds.) Toward a common destiny (pp. 315-339). SanFrancisco, CA. Jossey-Bass, inc.

Banks, J. A. (1997a). Multicultural education: Characteristics and goals. InJ.A. Banks \& C.A.M. Banks (Eds.), Multicultural education: Issues and perspectives(pp. 3-31). Boston: Allyn and Bacon.

Banks, J. A. (1997b). Approaches to multicultural curricular reform. In J.A.Banks\& C.A.M. Banks (Eds.), Multicultural education: Issues and perspectives(pp. 229-250). Boston: Allyn and Bacon.

Bannerji, H. (2000). The dark side of the moon. Toronto: Canadian ScholarsPress.

Boykin, A. W., Albury, A., Tyler, K., Hurley, E., Bailey, C., \& Miller, O. (2005).Culture-based perceptions of academic achievement among lowincomeelementarystudents.Cultural Diversity and Ethnic Minority Psychology, 11, 339-350.

Castaneda, C. R. (2004). Teaching and learning in diverse classrooms. NewYork: RoutledgeFalmer.

Chávez, A. F., Guido-DiBrito, F., \& Mallory, S. L. (2003).Learning to valuethe "other": A framework of individual diversity development. Journal of CollegeStudent Development, 44(4), 453-469.

Cuff, P. A., \&Vanselow, N. (2004).Improving medical education: Enhancing the behavioral and socialscience content of medical school curricula. Washington DC: The National Academies Press.

Dei, G. J. S. (1996). Anti-racism education: Theory and practice. Halifax:Fernwood Publishing.

Dogra, N., Reitmanova, S., \& Carter-Pokras, O. (2009). Twelve tips for teaching diversity andembedding it in the medical curriculum. Med Teach, 31(11), 990993.http://dx.doi.org/10.3109/014215 90902960326

Dogra, N., Reitmanova, S., \& Carter-Pokras, O. (2010). Teaching cultural diversity: current status inU.K., U.S., and Canadian medical schools.J Gen Intern Med, 25 Suppl 2, S164168.http://dx.doi.org/10.1007/s11606 -009-1202-7

Chang, M. J., Denson, N., Sáenz, V., \&Misa, K. (2006). The educational benefits of sustaining cross-racial interaction among undergraduates. The Journalof Higher Education, 77(3), 430-455.

Cunningham, R. T. (2005). Capitalizing on the cultural assets of African American children: Elevating schoolrelevant cognition with movement and music. In S.Battle (Ed.) The State of Black Baltimore. CSU Press: Baltimore, MD.

Cunningham, R. T., \& Boykin, A. W. (2005).Enhancing the cognitive (and school) performance of African American children: The infusion of Afro-cultural research-based 
practices. In R. Jones (4th ed) Black Psychology (pp. 487-508).Cobb and Henry: Hampton, VA.

Gay, G. (2000). Culturally responsive teaching: Theory, research and practice.New York: Teachers College Press.

Guo, S. \&Jamal, Z. (2007). Nurturing Cultural Diversity in Higher Education: A Critical Review of Selected Models.The Canadian Journal of Higher Education; 37, 3; CBCA Educationpg. 27

Gurin, P. Y. (1999). Expert report of Patricia Gurin, Gratz et al. v. Bollingeret al., No. 97-75321, Grutter et al. v. Bollinger et al. Retrieved February 8, 2007 , from the University of Michigan Web site: http://www.vpcomm.umich.edu/admi ssions/legal/expert/gurintoc.html

$\mathrm{Hu}, \quad$ S., \&Kuh, G. (2003).Diversity experiences and college student learningand personal development. Journal of College Student Development, 44(3),320-334.

Hurley, E. A., Allen, B. A., \& Boykin, A. W. (2009).Culture and the interaction of student ethnicity with reward structure in group learning. Cognition and Instruction, 27(2), 121-164.

James, C. E. (2000). Experience difference. Halifax: Fernwood.

Jones, E. B. (2004). Culturally relevant strategies for the classroom. In A.M.Johns\& M. K. Sipp (Eds.), Diversity in college classrooms: Practices for today'scampuses (pp. 51-72). Ann Arbor: University of Michigan Press.

Jules-Rossette (1986). Interpretive sociology in comparative perspective: paradigms andprospects. Canadian Journal o f Sociology.11.401-417.

Kitano, M. K. (1997). A rationale and framework for course change. In A.I. Morey \& M. K. Kitano, (Eds.), Multicultural course transformation in highereducation: A broader truth (pp. 1-17). Boston: Allyn and Bacon.

Marshall, P. (2002). Cultural diversity in our schools. Belmont: ThomsonLearning.

Orfield, G.,Kurlaender, M. (2001). In defense of diversity: New research and evidence from the University of Michigan. Equity and Excellence in Education, 32(2), 31-35.

Pike, G. R., \&Kuh, G. D. (2006). Relationships among structural diversity,informal peer interactions and perceptions of the campus environment. TheReview of Higher Education, 29(4), 425-450.

Sanner, S.,Baldwin, D.,Cannella, K.,Charles, J. (2010).The Impact Of Cultural Diversity Forum On Students' Openness To Diversity. Journal of Cultural Diversity; Summer 2010; 17, 2; Public Health Databasepg. 56

Shibao, G \&Zenobi, J. (2007).Nurturing Cultural Diversity in Higher Education.Canadian Journal of Higher

EducationRevuecanadienned'enseign ementsupérieurVolume 37, No. 3, 2007 , pages 27-49. www.ingentaconnect.com/content/css he/cjhe

Wlodkowski, R. J., \& Ginsberg, M. B. (1995). Diversity and motivation:Culturally responsive teaching. San Francisco: Jossey-Bass. 